\title{
Sentir, hacer y ser: sobre la interacción temporal de los aprendizajes inconscientes de un docente
}

Antonio Hidalgo Torres

Docente del Centro de Investigaciones en Educación, Escuela de Ciencias de la Educación, UNED.

San José, Costa Rica; ajosue28f@yahoo.com

Recibido: 14 de octubre del 2017

Corregido: 20 de noviembre del 2017

Aceptado: 22 de marzo del 2018

\section{Resumen}

El artículo se dedica a estudiar tres dimensiones de los aprendizajes inconscientes de un docente: las tonalidades del sentir, las estrategias del hacer y los equilibrios del ser. Los aprendizajes inconscientes son conceptualizados como procesos que denotan una interacción temporal entre el pasado del docente (experiencias estudiantiles) y el presente del docente (clima de clase gestionado). La investigación realizada se asume como una posible interpretación y/o explicación del quehacer docente y de la cotidianidad educativa, a partir de técnicas como la observación, la entrevista y la narrativa.

Palabras clave: docente, aprendizajes inconscientes, experiencias estudiantiles, clima de clase, interacción temporal.

\section{Abstract \\ Feeling, doing and being: about the temporal interaction of the unconscious learning of a teacher.}

The article is devoted to study three dimensions of the unconscious learning of a teacher: the tonalities of feeling, the strategies of doing and the balances of being. These unconscious learnings are conceptualized as processes that denote a temporal interaction between the teacher's past (student experiences) and the teacher's present (managed class environment). The research carried out is assumed as a possible interpretation and / or explanation of the teaching task and of the educational daily life, from techniques such as observation, interview and narrative.

Key words: Teacher, unconscious learning, student experiences, class environment, temporal interaction.

\section{INTRODUCCIÓN}

Sentir, hacer y ser: tres dimensiones de un mismo sujeto docente, tres aspectos que se derivan de su historia de vida escolar y de su praxis como enseñante, tres carrefours o puntos de entrecruzamiento de temporalidades: pasado y presente. Constituyen, además, tres habilidades aprendidas y utilizadas como estrategias para enfrentar el acto de enseñar. El propósito de este artículo está orientado a explicar la existencia de ciertas correspondencias entre las experiencias estudiantiles de un docente y su actuar. Tales correspondencias se enfocan en aspectos de tipo socioafectivo. Entonces, el texto busca analizar 
un pasado socioafectivo recordado y aprendido por un docente, el cual es utilizado en acciones presentes ejecutadas durante la labor de enseñanza.

Una premisa elemental de la investigación consiste en el posicionamiento teórico-conceptual sobre la educación. ¿Cuál es la forma de entender la educación? Ante todo se parte del hecho de que la educación es un fenómeno social y un ámbito social, construidos por la sociedad en la cual se inscribe. La educación como fenómeno social adquiere dos consideraciones, primero la educación es generada socialmente y segundo la educación reelabora la sociedad que la originó; de allí la importancia de comprender la educación como un proceso socio-constructivo y/o sociocultural (Sarramona, 2008).

Respecto al segundo término, ámbito social, la conceptualización de la educación debe conllevar una comprensión de lógicas de interrelaciones. La educación al ser construida socialmente, se encuentra indiscutiblemente vinculada con otros ámbitos de la sociedad, el sociólogo francés Émile Durkheim planteaba que "cuando se estudia históricamente la manera en la cual se formaron y desarrollaron los sistema educativos, es posible percibir que estos sistemas dependen de la religión, de la organización política, del grado de desarrollo de las ciencias, del estado de la industria, etc." ["Iorsqu'on étudie historiquement la manière dont se sont formés et développés les systèmes d'éducation, on s'aperçoit qu'ils dépendent de la religion, de l'organisation politique, du degré de développement des sciences, de l'état de l'industrie, etc."] (Durkheim, 2002, p. 6). Dicho interaccionismo contribuye a una visión global de la educación, donde cada uno de sus componentes (actores, instituciones, discursos, prácticas, y demás) es generado por una sociedad y generadores de ella misma.

Esta perspectiva se acerca a los planteamientos socio-culturalistas de Vygotsky, al plantear la educación y los procesos de aprendizajes en entera relación con el medio en el que se generan y dependientes de los actos interactivos producidos entre los sujetos (Román, Martínez y Pérez, 1999, p. 207). La investigación que se detalla en estas páginas concibió la educación desde esta perspectiva sociocultural, recurriendo a un docente específico como sujeto de estudio y dimensionándolo en sus distintos ambientes educativos (actores, espacios, interacciones), de los cuales, aquellos del pasado moldearon sus nociones del actuar docente, mientras que los del presente le estimulan a recuperar dichas nociones y a utilizarlas. Al proceso de interacción temporal y de almacenamiento no predispuesto de nociones sobre el ser/ actuar docente se le ha denominado en esta investigación como: aprendizajes inconscientes.

La comprensión de la educación como fenómeno y ámbito social, el estudio de la interacción pasado y presente en un docente específico, y el análisis de los aprendizajes inconscientes, definitivamente acerca al posicionamiento analítico de "la perspectiva compleja de la relación [praxis] educativa" ["l'approche complexe de la relation [praxis] éducative"] (Go, 2009, p. 7). Es decir, estudiar un problema y escudriñarlo en su pluralidad de determinantes; profundizar, en este caso, en un docente acercándose a sus recuerdos, a sus procesos de interacción, a su emocionalidad y a su corporalidad, adentrarse en su presente que es el quehacer cotidiano; $y$ luego interpretar y establecer posibles correlaciones. Todo ello promovió solicitar ayudas de otras disciplinas como las estrategias metodológicas de la antropología y el bagaje teórico que desde la historiografía se ha realizado por los vínculos pasado y presente, pero también echar mano de la psicología y sus conceptos psicoanalíticos del inconsciente, para conjugar todo eso con la teoría educativa. Complejidad es sinónimo en la investigación realizada de profundidad, minuciosidad e interdisciplinariedad.

Cuatro partes, antes de las conclusiones, conforman el cuerpo de este documento, un primer apartado sobre los aspectos teórico metodológicos, seguido de tres secciones enfocadas en el sentir, el hacer y el ser como conceptos englobantes de los aprendizajes inconscientes del docente sujeto de estudio (DSE). 


\section{UN ENFOQUE Y UNA ESTRATEGIA: HERRAMIENTAS TEÓRICAS Y METODOLÓGICAS}

\section{Marco teórico}

Al revisar el trabajo de Jackson (1996), sobre la vida en las aulas, cuando el investigador explica la opinión y la actuación del cuerpo docente en el interior del salón de clases, anota que "cuando se les pedía, por ejemplo, que justificasen sus decisiones profesionales, mis entrevistados declararon a menudo que su conducta en el aula estaba determinada por impulsos y sentimientos más que por reflexiones y pensamientos" (p. 178). De esa cita se coliga un planteamiento crucial, la existencia de una actuación docente no razonada, que el autor señala impulsiva y sentimental, y que en otro momento precisa como "intuitiva".

Para Jackson (1996), como para Torres (1996), existen acciones y nociones en el profesorado que son implícitos, imperceptibles, automáticos e, intuitivos, y se presentan en el quehacer cotidiano. los autores no ubican una explicación para tales situaciones, entonces es ahí donde esta investigación entra en juego. La propuesta del artículo es dar una explicación a las acciones socioafectivas "automáticas", que aquí se llamarán "inconscientes", que el DSE ejecuta en su gestión del clima de clase.

Las acciones inconscientes que se estudiarán son las relaciones socioafectivas que propicia el profesorado en el presente, originadas en el pasado docente. Lo que aquí se llama "origen" tiene la forma de un aprendizaje inconsciente. Es decir, el profesorado adquirió estructuras de acción docente en el ámbito socioafectivo en su experiencia estudiantil, sin que tales estructuras fueran explícitamente enseñadas, sino que a través de la interacción y de la cotidianidad se le fueron incorporando en su bagaje mental.

El concepto de aprendizaje inconsciente remite a una característica que ya mencionaba Freud (2009) sobre la influencia y procedencia social de la definición de los niveles conscientes e inconscientes del yo. Resulta necesario acudir a Freud, en tanto permite considerar que ciertos aprendizajes inconscientes del DSE se generan por la socialización educativa que enfrentó como estudiante, estableciendo en el inconsciente docente estructuras de acción en su práctica pedagógica en el ámbito socioafectivo.

Esas estructuras inconscientes que se han mencionado se presentan en dos procesos, para definirlos se recurre a Núñez (1998), quien indica:

- Proceso inconsciente primario: o proceso de abajo-arriba, ya que consiste en la adquisición imperceptible de estructuras o conocimientos no explícitos, los cuales provienen desde afuera del individuo, y que se almacenan en la mente del sujeto.

- Proceso inconsciente secundario: o proceso de arriba-abajo, este se presenta cuando aquellas estructuras o conocimientos inconscientes se traducen en reacciones espontáneas y "naturales" (inconscientes) ante situaciones parecidas a aquellas en las que se habían adquirido las estructuras inconscientes. Por tanto, de un almacenaje inconsciente en la mente se pasa a una acción inconsciente externa. (p. 31)

Entonces al proceso primario se le llamaría "adquisición inconsciente" y al proceso secundario "aplicación inconsciente", juntos los dos procesos dan como resultado un solo macro-proceso: "aprendizajes inconscientes". Temporalmente, la investigación ubica al proceso primario en el pasado y al secundario en el presente; de esta forma se genera una interacción temporal entre el pasado (experiencias estudiantiles docentes) y el presente (clima de clase) del cuerpo docente. Al hacer referencia al concepto de interacción temporal se busca indicar que se genera un "contacto" entre ambas temporalidades. 
Dos conceptos se tornan clave de articular junto al de aprendizajes inconscientes, estos son el pasado en su forma de experiencias estudiantiles y el presente en su forma de clima de clase socioafectivo.

Tratar las experiencias estudiantiles del DSE es partir del hecho de que las vivencias escolares (pasadas) tienen algo que decir sobre cada docente (en el presente). Es establecer una interrelación de temporalidades manifiesta en la identidad y la formación profesional, que a su vez se hace presente en el accionar cotidiano del profesorado en el salón de clases. Además, es aceptar que la noción sobre la labor docente se genera desde la infancia, cuando se desarrollan los primeros contactos de una persona con el mundo escolar. En palabras de Alliaud (1998),

La trayectoria escolar incluye todas las etapas de la escolaridad previa: jardín de infantes, escuela primaria, secundaria y aun la formación profesional. De este modo la biografía escolar constituye una instancia formativa con importantes efectos en el ejercicio profesional de los docentes. (p. 3)

Variados temas pueden estudiarse del conjunto de experiencias estudiantiles, entre ellas destacan el clima afectivo de la clase y el vínculo docente-alumno. Alliaud (2004), refiriéndose a la afectividad en las experiencias estudiantiles, enfatiza en la figura de cada maestro y el trato hacia el grupo estudiantil, "absolutamente relacionado con el tema de la afectividad y en ciertos casos con las vivencias personales, aparece en algunos relatos la ayuda que el maestro brinda a los alumnos como otro ingrediente propio de la tarea de enseñar" (p. 7).

Desde la perspectiva de complejidad analítica, el concepto de clima de clase puede ser considerado como un aspecto inmaterial, subjetivo y ante todo psicológico de lo que Ortega (1990) denomina el "grupo-aula". Entonces el clima de clase es una construcción de interacciones y percepciones producida por cada uno de los actores (docente, estudiante), y a la vez todos como conjunto, insertos en el espacio del aula. Marchena (2005) citado por Barreda (2012) señala la siguiente conceptualización: "es una construcción originada por las relaciones sociales que entablan los protagonistas de una clase así como por la forma de pensar de cada uno de ellos, por sus valores, esto es, por la cultura existente en el aula" (p. 5)

En todos los aspectos citados, el enseñante tiene un rol crucial como gestor-propiciador de acciones desencadenantes de atmósferas educativas, de allí la importancia de estudiar la figura del docente sus experiencias, percepciones, identidad(es) y actuaciones. Sobre este tema, Mejía y Ávila (2009) concluyen a partir de su investigación que: "nuestros resultados nos conducen a reconocer la importancia del contexto sociocultural de la escuela, en el cual pudo o no haber sido formada la profesora, para comprender la conformación de normas sociales en torno a la confianza" (p. 503). Esta cita pone en evidencia que las interacciones socio-afectivas gestionadas por docentes pueden verse influenciadas por el bagaje experiencial propio de su vida como estudiante

El recorrido conceptual realizado se ha orientado al desarrollo del enfoque analítico que se propone en este artículo, el cual consiste en comprender que el DSE posee un bagaje experiencial de su trayectoria como estudiante de primaria, secundaria y universidad que le permite adquirir nociones sobre la praxis de un docente, las cuales fueron almacenadas de forma imperceptible y generalmente simultáneamente (Núñez, 1998, pp. 34-35). Las nociones son recuperadas y "reproducidas" en el presente cuando las situaciones del clima de clase se correlacionen con aquellas vividas en el pasado. A este proceso de interacción temporal de las experiencias estudiantiles y del clima de clase se le ha denominado: "aprendizajes inconscientes".

Con base en el despliegue teórico que se ha planteado se llega a una interrogante fundamental que incita al desarrollo de la investigación, dicho problema de investigación se plantea así: ¿existe correspondencia entre las experiencias estudiantiles de un docente y su actuar como docente? y si es afirmativa la interrogante entonces ¿cuáles y cómo son esas correspondencias? 


\section{Metodología}

La investigación tiene carácter cualitativo e interpretativo. Se recurrió a un docente específico' como sujeto de estudio, de allí que la investigación sea un estudio de caso. Pero además participaron dos grupos de undécimo año quienes fueron estudiantes del DSE. La etapa de recolección de datos se realizó en dos momentos, primero para acceder a la información sobre el pasado estudiantil se utilizó la técnica de la narrativa docente (Reis y Climent, 2012) y de la entrevista a profundidad al DSE. Por otra parte, el segundo momento, dedicado al estudio del presente del docente o el clima de clase, se utilizó la técnica de observación directa (y la construcción de un diario de campo), se aplicaron entrevistas a profundidad a tres estudiantes que decidieron participar, así como al docente; además de la narrativa de estudiantes sobre momentos y formas de recordar al DSE. Se debe indicar que el proceso de solicitud de autorizaciones paso en un primer momento por el permiso institucional (en la figura del director), seguido por la consulta y convencimiento de la participación del docente, y finalizando con los permisos de padres de familia quienes autorizaron la participación del estudiantado.

Una vez recolectada la información, para el caso de las entrevistas se transcribió cada una de ellas, las narrativas fueron pasadas a digital y los diarios de campo se realizaron directamente en la computadora. Posteriormente, se aplicó un análisis semiótico de la información que sigue la forma de descomposición de los datos recolectados, se continúa con la extracción de significados y se culmina con la recomposición, que es en sí mismo el acto interpretativo (Pérez, 2012, pp. 102-103).

Para facilitar la presentación de los datos se utilizará el siguiente conjunto de abreviaturas:

TABLA 1

Tabla de abreviaturas

\begin{tabular}{cl} 
Abreviatura & \\
DSE & Docente Sujeto de Estudio \\
P & Entrevistador \\
E & Entrevistado \\
TEE & Transcripción Entrevista Estudiantado: El clima de clase gestionado por el DSE \\
\hline TED1 & Transcripción Entrevista Docente 1: Experiencias Estudiantiles del Docente \\
\hline TED2 & Transcripción Entrevista Docente 2: El Clima de su Clase \\
\hline DC1 & Diario de Campo-1 \\
DC2 & Diario de Campo-2 \\
TND & Transcripción de Narrativas del Docente: Experiencias Estudiantiles del Docente \\
TNE & Transcripción de Narrativa Estudiantado: Experiencias con el DSE
\end{tabular}

Fuente : Hidalgo-Torres, 2016, p. 82.

1. Se seleccionó a un docente accesible que estuvo de acuerdo con el proceso de recolección de datos que requería la investigación. Téngase presente que mucha de la información que se debía recabar podía ser material muy sensible y de mucho valor al ser especialmente recuerdos y experiencias. 


\section{RESULTADOS}

A continuación se va muestra el análisis de los resultados, para ello se recurre a una prosa explicativa centrada en tres categorías que se lograron identificar una vez recolectados los datos. Para cada categoría se establecen subcategorías, con el fin de explotar con mayor profundidad la información recolectada. Asimismo, se usa la información de los múltiples instrumentos para sustentar cada uno de los argumentos, interpretaciones y explicaciones que se desarrollan a lo largo de las páginas siguientes. Las tres categorías corresponden a: Tonalidades del sentir, Estrategias del hacer y Equilibrios del ser.

\section{Tonalidades del sentir}

Tonalidades del sentir es un análisis sobre las distintas formas en que los sentimientos y emociones se presentan en la dinámica áulica. Es reconocer que el DSE en sus múltiples experiencias estudiantiles fue partícipe de distintos estados emocionales asociados con variadas situaciones y que, en el clima de clase, en su presente como docente, el DSE puede llegar a utilizar ese bagaje experiencial para hacerle frente a su labor docente. El apartado es, además, un reconocimiento a que la labor educativa, la dinámica educativa y, el mundo educativos no puede estudiarse y considerarse en sentido separado de lo emocional, sino que, como todo ámbito humano, lo emocional es transversal y omnipresente.

\section{El aula: un lugar emocional}

El espacio áulico representa además de un ámbito de enseñanza y aprendizaje, un espacio donde confluyen distintas personas vistas en su forma integral, por tanto, en estos espacios por consecuencia confluyen las distintas emociones de los mismos. En relación con esta dimensión espacial significativa cabe preguntarse ¿existieron en la trayectoria del DSE, como estudiante, espacios cargados emocionalmente, de forma tal que se conviertan en espacios significativos?, además ¿cuáles son las cargas emocionales que puede contener el espacio aula según el DSE?

En este sentido, al referirse el DSE a la emocionalidad relacionada con la espacialidad educativa en sus experiencias estudiantiles es posible notar como el recuerdo de un aula o de una institución demuestran que no existe una sola posibilidad, sensorial, sino que los cambios emocionales pueden sucederse. Un ejemplo de ello es cuando el DSE indica el cambio emocional que sufre en relación con una docente, véase la siguiente cita:

De primaria recuerdo a Doña Emérita, la maestra que tuve de primero a tercer grado, porque me marcó, en primero porque fue muy linda, muy tierna, muy todo y muy niña pochita, como todas las maestras de esa época, no sé ahora. Y todo lo que me enseñó a escribir me acuerdo los trazos, a hacer las letras del abecedario y aquel orden de las cosas. En tercero fue cuando pasó aquella experiencia que está en el escrito, y de a partir de ahí la odié. (TED1, 2016, p. 1).

Nótese la variación emocional que fue decantada por la actitud de la docente. Leyendo los comentarios del estudiantado sobre el clima de clase propiciado por el DSE se puede encontrar una correspondencia al considerar que el aula no es un espacio monolítico emocionalmente. La siguiente frase da cuenta de la variación que suscita el DSE en su clase: "En una clase con el profesor pueden pasar muchas situaciones, buenas, malas, alegres, etc" (TNE, 2016, p. 5). 
La variabilidad de los estados anímicos en el aula también se evidencia en las siguientes observaciones:

[Observación del DSE:] no me gusta que se vayan bravos y cuando ha pasado algo así yo siempre les hago ver de donde sale la molestia para que ellos entiendan y ya después se relaja la clase, las clases yo las siento que..., siempre trato de terminar la clase relajado, que no termine en un pico de bravura ni nada. (TED2, 2016, p. 1)

[Observación del estudiantado sobre el momento en que el DSE da la lección:] No es lo mismo, él en ese momento puede estar hablando del tema y sale una cosa y él puede vacilar y se vuelve a meter en el tema, pero siempre fijándose en el tema, él cuesta mucho que uno pierda clases con él [...]. (TEE, 2016, p. 2)

En ambos casos se puede apreciar cómo el ambiente del aula presenta alternancia de los estados anímicos, DSE mencionaba un cambio de bravura a relajación, mientras que el estudiante colaborador nota esa variación a partir de la seriedad y el acto de vacilar.

Surge la pregunta en este momento sobre ¿cuáles son esas tonalidades emocionales que pueden percibirse en el clima de la clase y que tienen correspondencia con las experiencias estudiantiles del DSE? Para ello se van a detallar algunas de esas tonalidades emocionales que se pudieron encontrar en el clima de la clase y al mismo tiempo establecer la vinculación con el pasado.

Las variaciones emocionales pueden fluctuar desde lo positivo hasta lo negativo, si es que es válida la calificación polarizada, no obstante, se usa ese binomio positivo-negativo como estrategia que facilita la comprensión del análisis. Al iniciar la entrevista con el DSE y solicitar que definiera el clima de su clase el DSE, aparte de otras particularidades, indica que los estudiantes "se sienten felices" (TED2, 2016, p. 1). Esto puede mostrar que para el DSE resulta esencial que la felicidad o la alegría constituyan un componente fundamental en su labor como docente, y por tanto el aula debe constituirse en un espacio con cargas positivas y de bienestar para los sujetos interactuantes en dicho lugar.

Contrario a la felicidad se puede ubicar el disgusto del cual se encontraron dos tipos de matices: el primero corresponde al disgusto entre estudiantes; el segundo es un disgusto generado por el ambiente, el cual provoca una actitud estudiantil, sea una reducción del rendimiento académico o un cambio del comportamiento en el aula.

Estos dos tipos de tonalidades, la de felicidad y la de disgusto, constituyen los dos polos máximos. El aula constituye un espacio en el cual se presentan una serie de aprendizajes que aquí se han denominado inconscientes y que se encuentran relacionados con las formas y tonalidades del sentir. Los aprendizajes mencionados son la noción del aula como espacio cambiante, la variedad de tonalidades emocionales (felicidad, disgusto, tristeza, familiaridad y confianza) y las variaciones tonales dentro de cada conjunto emocional (ejemplos los casos de la felicidad y el disgusto).

\section{Sujetos emocionales}

Los sujetos que interactúan en el marco espacial constituyen entes emocionales y recurren a ciertas estrategias de expresión emotiva. Una primera estrategia que se puede identificar en la demostración de emocionalidad es la corporalidad. Es decir, a través del uso del cuerpo mediante un gesto, un contacto corpóreo, una mirada, entre otros, un sujeto puede comunicar su estado emocional. 
TABLA 2

Usos del cuerpo para la expresión emocional

\begin{tabular}{|c|c|c|}
\hline Uso del cuerpo & Experiencias estudiantiles del DSE & $\begin{array}{l}\text { Clima de clase gestionado } \\
\text { por el DSE }\end{array}$ \\
\hline $\begin{array}{l}\text { Abrazo como forma } \\
\text { de expresión }\end{array}$ & $\begin{array}{l}\text { Me sentí tan solo y con muchos sentimientos encontrados sin tener a } \\
\text { quien abrazar y me abrazara. (TND, 2016, p. 2) }\end{array}$ & $\begin{array}{l}\text { Pero ya en quinto es muy explícito el } \\
\text { cariño, el afecto, el abrazo. (TED2, 2016, } \\
\text { p. 4) }\end{array}$ \\
\hline $\begin{array}{l}\text { Contacto corporal } \\
\text { como forma de } \\
\text { cercanía }\end{array}$ & $\begin{array}{l}\text { Había que dormir en una tienda de campaña en media montaña, o bajo } \\
\text { la lluvia, y el que podía conseguir tienda de campaña invitaba a uno, dos, } \\
\text { tres o cuatro para dormir en la tienda de campaña, eh sino amanecer } \\
\text { bajo de un árbol, en unas piedras, hasta que amaneciéramos, y así, } \\
\text { osea, nos acomodábamos de acuerdo afinidad, o muchas cosas, los que } \\
\text { cupiéramos, en una cama dormíamos dos, o tres, y o dos en el suelo, y el } \\
\text { otro día dormía uno en la cama y le llevábamos todo ese tipo de cosas. } \\
\text { (TED1, 2016, p. 27) }\end{array}$ & $\begin{array}{l}\text { Entonces ya en quinto ya es más } \\
\text { explícito el cariño de ambos lados, } \\
\text { el abrazo, ellos me abrazan, me dan } \\
\text { la mano y me tocan el hombro y se } \\
\text { atreven a tocarme, osea el contacto } \\
\text { físico y en grupo verdad, no en forma } \\
\text { individual porque no, no debemos por } \\
\text { los protocolos verdad. (TED2, 2016, p. 4) }\end{array}$ \\
\hline
\end{tabular}

Fuente: Elaboración propia (TED1, 2016; TED2, 2016; TND, 2016).

En los datos del tabla se puede notar que el uso del cuerpo para la expresión emocional es un aprendizaje inconsciente que se manifiesta igualmente en la clase. Más que el hecho mismo del contacto corporal, resulta importante en la dinámica del aula el contenido emocional con el que se encuentra cargado el uso del cuerpo, en el primer caso se nota como la falta de un abrazo es sinónimo para el DSE de carencia de acompañamiento, así el DSE utiliza el abrazo justamente para expresar la compañía y el afecto por el estudiantado.

Asimismo, en el segundo ejemplo sobre sus experiencias estudiantiles el DSE relaciona el contacto y conocimiento corpóreo del dormir juntos como una forma de familiaridad y cercanía; así entonces durante la gestión del clima de clase el contacto físico nuevamente se presenta como una forma de proximidad.

Junto a la corporalidad, las palabras constituyen otra estrategia por medio de la cual los sujetos expresan su afecto, sin ser tangibles como el uso del cuerpo. Por la versatilidad del empleo de la palabra, se pueden encontrar varios usos, entre ellos: la comprensión del otro, el estímulo positivo, el reconocimiento social del otro, la sanción y la agresión. Los usos de la palabra pueden manifestarse de forma escrita u oral. 
TABLA 3

Palabras utilizadas para expresar el afecto

\begin{tabular}{|c|c|c|}
\hline $\begin{array}{l}\text { Función de la } \\
\text { palabra }\end{array}$ & Experiencias estudiantiles del DSE & Clima de clase gestionado por el DSE \\
\hline $\begin{array}{l}\text { Comprensión } \\
\text { del otro }\end{array}$ & $\begin{array}{l}\text { Mis queridos profesores, Carmen de inglés, Rosita } \\
\text { de español, Fray Lecera de matemática, la de fran- } \\
\text { cés, bueno todos, me tomaron cariño y siempre me } \\
\text { buscaban para ver cómo estaba. (TND, 2016, p. 4) }\end{array}$ & $\begin{array}{l}\text { "Además de ser un excelente profesor es una gran persona, nos } \\
\text { ha aconsejado y enseñado muchas cosas sobre la vida y en el } \\
\text { futuro lo voy a recordar de la misma forma ya que forma parte } \\
\text { importante de nuestras vidas =)". (TNE, 2016, p. 2) }\end{array}$ \\
\hline Estímulo positivo & $\begin{array}{l}\text { Él nos felicitaba y me felicitaba personalmente } \\
\text { me decía: “Lo felicito, vea el esfuerzo, sí se puede } \\
\text { [nombre del DSE], sí puede lograrlo”, y ese constan- } \\
\text { te felicitación hacia uno que se motivara aún más. } \\
\text { (TED1, 2016, p. 14) }\end{array}$ & $\begin{array}{l}\text { El año pasado casi, casi, casi por poquito me quedo, y casi no } \\
\text { estoy aquí en quinto, y con él, pero él me dijo que: "Todo lo que } \\
\text { le pusiera esfuerzo en la vida tendría su recompensa” y enton- } \\
\text { ces yo me mordí estudiando en convocatoria, solo a sociales } \\
\text { me fui a convocatoria. Y me dice: "Yo sé que, que usted, que } \\
\text { usted va a pasar" y me mordí estudiando y cuando me dio él, } \\
\text { la nota me dice: "Uy que mala noticia”, y yo le digo: “Qué?", me } \\
\text { dice: "Pasó", me vaciló y... pero, pero... (TEE, 2016, p. 4) }\end{array}$ \\
\hline Sanción & $\begin{array}{l}\text { Entonces la sanción de él era rompernos los traba- } \\
\text { jos, nos decía: “Esta cochinada, este mapa, [nombre } \\
\text { del DSE], este mapa mal hecho". (TED1, 2016, p. 24) }\end{array}$ & $\begin{array}{l}\text { A mí me ha regañado cuando he hecho cosas así, yo me he } \\
\text { jalado varias tortas... (TEE, 2016, p. 3) }\end{array}$ \\
\hline Agresión & $\begin{array}{l}\text { Veía que regañaban y le decían de lo peor a un } \\
\text { compañero: "Usted es un burro, usted no sirve para } \\
\text { nada, usted que está haciendo aquí, mejor se va", de } \\
\text { maltrato verbal, los castigos eran maltratos verbales, } \\
\text { y exponían a un compañero o compañera. (TED1, } \\
\text { 2016, p. 14) }\end{array}$ & $\begin{array}{l}\text { E: Bueno es que en mi aula yo no les permito que se golpeen, ni } \\
\text { que se ofendan, yo no sé allá fuera pero yo aquí no les permito } \\
\text { así que se digan tal por cual, o que se ofendan, o que lo agarren } \\
\text { de minga como le llama uno verdad, que agarren de minga a } \\
\text { uno no lo permito, eh, que se burlen de alguien jamás. (TED2, } \\
2016, \text { p. 12) }\end{array}$ \\
\hline
\end{tabular}

Fuente: Elaboración propia (TED1, 2016; TED2, 2016; TEE, 2016; TND, 2016; TNE, 2016).

Los usos de la palabra son comprendidos como aprendizajes inconscientes en tanto el lenguaje constituye un constructo sociocultural, así los procesos de socialización tanto del pasado y del presente van modulando los espacios y momentos de utilización. Los primeros tres usos mencionados en el tabla muestran una correspondencia entre pasado y presente, es decir entre experiencias estudiantiles del DSE y el clima de clase; no obstante, en la última, el uso agresivo del lenguaje, la relación que existe entre experiencias y clima de clase es opuesta, no es un empleo agresivo del lenguaje sino una prohibición para evitar un daño de tipo emocional como al que refiere el DSE en su experiencia.

Este apartado pudo constatar que existen formas y variaciones emocionales del clima de clase que tienden a relacionarse con aquellas que experimentó el DSE en su pasado. Como gran aprendizaje inconsciente, se resalta la concepción de que la educación es un acto complejo de emocionalidad, sensibilidad y sentimentalidad, lejos de una "frialdad" academicista, la educación constituye un hacer y un pensar sumergido en la cambiante emocionalidad humana. Por lo tanto, se propone comprender las tonalidades emocionales educativas como aprendizajes inconscientes, que requieren hacerse conscientes en el quehacer cotidiano educativo.

\section{Estrategias del hacer}

Las "estrategias del hacer" engloban aquellas acciones a las que recurre el DSE para mostrarse como docente frente a sus estudiantes. Se pueden distinguir, al respecto, dos construcciones realizadas por el DSE en su presente laboral a partir de sus experiencias estudiantiles, tales constructos, por tanto, constituyen aprendizajes inconscientes. 


\section{Construyendo una imagen}

EI DSE al mostrarse ante los estudiantes elabora una imagen de sí asumiendo el rol docente, por tanto, adquiere características específicas que de alguna manera están ligadas a las figuras docentes con las cuales se relacionó durante su periodo de estudiante. La imagen construida se fundamenta en tres ejes: la disciplina, la responsabilidad y la creatividad.

Disciplina: ¿en su etapa como estudiante el DSE socializó con figuras que comparten esa característica? La maestra Merayo en primaria es una de esas figuras al respecto indica el DSE:

La niña Merayo llegaba con mucho material [...] cuando ella explicaba era muy estricta eso sí verdad, me acuerdo que usaba un metro de madera y golpeaban la pared, la pizarra para empezar o el pupitre y era así que, era como muy disciplinado todo, y todo mundo en silencio, nos sentaban de dos en dos para trabajar. (TED1, 2016, p. 2)

Nótese, la correspondencia sobre el carácter, la responsabilidad y el silencio entre la cita anterior y las opiniones de los estudiantes colaboradores:

[Estudiante 1:] En mi lugar recordaré al profe, de una manera muy buena, porque siempre nos enseñó a ser responsables y unos ganadores, siempre brindó su ayuda. Otra cosa es que gracias a su carácter fuerte nos enseñó a ser estudiantes buenos y todos sus consejos nos ayudarán para el futuro. (TNE, 2016, p. 2)

[Estudiante 2:] La clase con el profesor la verdad es muy diferente porque es con mucho mas silencio y respeto que las demás, ya que él desde un principio nos inculco eso y así es mucho mejor aprender y poner atención. (TNE, 2016, p. 3)

En el transcurso de las entrevistas y las narrativas es posible constatar que tanto en el pasado como en el presente del DSE la disciplina y la responsabilidad son asociadas directamente con la puntualidad (TED1, 2016; TNE, 2016).

La creatividad también constituye otro elemento de esa imagen docente, la creatividad se asocia con la posibilidad de hacer comprensible y amena la materia impartida.

TABLA 4

La creatividad componente de la imagen docente.

\section{Experiencias estudiantiles del DSE}

De Historia Universal, Carlitos, terminando con nosotros murió, de SIDA, y nos impactó tanto porque las clases de él era, si era civilizaciones antiguas él llevaba hasta, de todo, esculturas, mantas de lo que fuera, de la India, de esto, porque él viajaba mucho, y las exposiciones que nos, nos lográbamos montar con él eran así de, como de película, nos permitía que nos vistiéramos, si era de faraón, o de Maya, o de emperadora Inca, pero las clases de él eran muy dinámicas, y nos traía mucho material y materia, y nos daba, y nos regalaba, nos decía: “No, no me lo paguen, yo se los regalo, tome le traigo estas filminas, tome le regalo esto" y las clases eran muy locas, con él, locas en el sentido que él era muy abierto a cualquier cosa. (TED1, 2016, p. 30)

Fuente: Elaboración propia (TED1, 2016; TEE, 2016).
Clima de clase gestionado por el DSE

Él lo que decía: “No me traigan a mí un cartel que siempre se ve, sorpréndanme, traigan otras cosas diferentes, y por eso antes en el aula que tenía ahí, tenía un montón de cosas, lo que era móviles y todo aah, un montón de cosas tenía. (TEE, 2016, p.)

Él trata de explotar nuestra creatividad de una forma en que nosotros nos quede eso porque, como muchas personas utilizamos la creatividad para aprender, entonces él busca la forma que todos aprendamos y las clases. (TEE, 2016, p. 13) 
Estos son tres ejemplos de componentes de la imagen docente que el DSE ha construido y que presenta ante sus estudiantes. Además, es posible notar que sus estudiantes las reconocen. No obstante, para efectos de esta investigación lo relevante es comprender que la imagen posee cierta correspondencia con el pasado que recuerda el DSE, por lo tanto, puede establecerse que las cualidades: la disciplina-carácter, la responsabilidad y la creatividad de la imagen conforman un conjunto de aprendizajes inconscientes.

\section{Construyendo un discurso}

En el actuar áulico del DSE existe un discurso sobre el esfuerzo que puede catalogarse como aprendizaje inconsciente, en tanto existen correspondencias entre el clima de clase y el pasado estudiantil docente.

Sobre el esfuerzo se puede encontrar en el clima de clase que el DSE ha calado en los estudiantes colaboradores un discurso sobre el aprendizaje como un acto producto del esfuerzo, de la constancia, de una lucha interior del individuo, pero también una noción del esfuerzo como un componente de la vida en general, léanse los siguientes ejemplos:

[Ejemplo 1 (esfuerzo en la vida):] Los consejos que él nos daba siempre de nunca darse por vencido. De luchar por nuestros sueños hasta el final. De nunca hecharse a morir por los problemas personales de uno. De no dejarnos de las personas que nos quiere perjudicar en la vida osea Alejarnos de ellas. Y siempre dar lo mejor de mí. (TNE, 2016, p. 1)

[Ejemplo 2 (esfuerzo en la educación):] El año pasado casi, casi, casi por poquito me quedo, y casi no estoy aquí en quinto, y con él, pero él me dijo que: "Todo lo que le pusiera esfuerzo en la vida tendría su recompensa" y entonces yo me mordí estudiando en convocatoria, solo a sociales me fui a convocatoria. (TEE, 2016, p. 4)

Al leer referencias como las anteriores entonces cabe preguntarse ¿qué aspectos de la vida como estudiante pudieron haber contribuido a formar un discurso educativo en el cual el esfuerzo se encuentra como un elemento constitutivo? En el conjunto de las narrativas estudiantiles del DSE se puede notar que subyace en esa construcción discursiva la necesidad de resaltar la lucha y el esfuerzo constantes como rasgos transversales en todas las etapas de la vida. EI DSE utiliza como elementos constantes del discurso la cuestión de los obstáculos y la adaptación, asimismo aparecen figuras que refuerzan esa noción de la vida y la educación como actos basados en el esfuerzo, véanse los siguientes extractos:

[Los obstáculos:] Tres días después me otorgaron la Beca 10 (dinero para pagar hospedaje, créditos de los cursos, libros de la biblioteca y desayuno y almuerzo en el comedor estudiantil. Se había resuelto otro obstáculo más. (TND, 2016, p. 8)

[La adaptación:] Bueno no tenía remedio, tuve que adaptarme para sobrevivir, pero poco a poco hice alianzas de estudio y de juegos, caí bien y me cayeron bien los nuevos compañeros (as). (TND, 2016, p. 2)

[La madre como figura que refuerza la noción de esfuerzo:] Entonces nada más mamá nos decía: "Esas son sus tareas tienen que cumplirlas" [realiza sonidos sobre la mesa acentuando la frase], y mi mamá llegaba en la noche revisaba y firmaba. (TED1, 2016, p. 5)

[La educación como un acto de esfuerzo y solidaridad:] Cuando alguno era flojo en alguna área le ayudábamos, nos ayudábamos en un área equis, este de conversiones matemáticas, porque todo esto de escalas o fotointerpretación se usa mucho la matemática y a mí me costaba esa parte, porque yo en las matemáticas no es mi fuerte entonces me ayudaban, pero yo ayudaba en otra cosa, y otros ayudaban en otra entonces nos, éramos muy unidos. (TED1, 2016, p. 26) 
En las citas anteriores se puede constatar que las nociones donde el esfuerzo, la entrega, la lucha son conceptos constantes en la forma de enfrentar y comprender la dinámica educativa, entendida como una dinámica que traspasa los límites áulicos. Por lo tanto, el discurso sobre el esfuerzo y sus ideas paralelas como obstáculos, adaptación y figuras que refuerzan la noción de esfuerzo, puede ser comprendido como un aprendizaje inconsciente pues se presenta en el clima de clase.

\section{Equilibrios del ser}

Se ha llamado a este último apartado del análisis: "Equilibrios del ser" porque resulta interesante considerar que al fin y al cabo todo el bagaje experiencial ha decantado en un sujeto que en su conformación ontológica como docente presenta como rasgos algunos "equilibrios" fundamentales para el establecimiento de interacciones y de relaciones en la dinámica del clima de clase.

\section{Profesor-amigo: equilibrio figurativo}

La conjugación de estas dos figuras profesor y amigo puede ser considerada como un aprendizaje inconsciente si se toma en cuenta que durante su etapa estudiantil, especialmente en colegio y universidad, el docente colaborador recuerda profesores cercanos a él, tanto que conocían su situación personal y familiar, que se divertían con él, que lo animaban a seguir adelante, pero que al mismo tiempo mantenía el respeto hacia ellos. La siguiente cita muestra la existencia de esas dos figuras docentes: un docente puramente profesor y una docente amiga (casi de la misma edad), lo importante de destacar es que para ambos el docente colaborador otorga una valoración positiva:

Había gente muy mayor, ya gente cuarentona, cincuentona y gente muy joven, los que eran muy mayores eran muy estrictos, muy, muy estrictos y de respeto, porque imponían el respeto, y uno decía Don Eliécer, me recuerdo de Don Eliécer en Pacayas que era el señor de administración rural que es una materia específica, llegaba Don Eliécer y aquel respeto, pero llegábamos con la orientadora un desmadre, todo mundo le caminaba en el piso y de todo, y allá en el techo, y tiraban los papeles y nadie le hacía caso pero era muy buena gente y todos pasábamos metidos en el cubículo de ella, principalmente yo. (TED1, 2016, p. 12)

Ahora, entre las narrativas que los estudiantes colaboradores realizaron sobre el DSE se puede apreciar como existe esa conjugación de figuras profesor y amigo:

[Ejemplo 1:] -El profe ha sido buena nota conmigo, la forma de explicar es excepcional, ya que usa métodos distintos de enseñanza con respecto a otros profesores, pienso que dentro de 10 años lo recordare por todas las vaciladas en el aula y la enseñanza que me brindo. (TNE, 2016, p. 2)

[Ejemplo 2:] Lo voy a recordar por el excelente Profesor, aparte de un buen amigo al que se le puede confiar. Por sus clases creativas el cual uno gozaba bastante. Lo voy a recordar por el buen comportamiento de el hacia nosotros. Por su carisma y humildad. (TNE, 2016, p. 2)

La conjunción entre la figura de profesor y de amigo es crucial en la conformación de un clima de clase positivo y cordial, constituye tanto una estrategia que el DSE utiliza para su labor docente, como un aprendizaje que el DSE pudo haber obtenido desde sus etapas como estudiante. 


\section{Disciplina-flexibilidad: equilibrio del poder}

Se legitima a nivel sociocultural al docente como persona poseedora de poder sobre un conjunto de individuos a los cuales se les denomina estudiantes. Se puede encontrar como elemento de la acción docente que ejerce el DSE que la administración del poder se lleva a cabo de forma tal que la rigidez que "aparentemente" caracteriza a la disciplina y al "buen" comportamiento se conjuga con la flexibilidad de la misma disciplina.

En otras palabras, que lejos de practicar y establecer normas rígidas de comportamiento, el DSE da cabida a relaciones de poder y a normativas maleables, adaptables a las circunstancias. En la entrevista sobre el clima de clase el DSE se refirió a la flexibilidad como primer aspecto característico:

[Entrevistado:] El clima de clase, o clima social, muy abierto, de mucha negociación, flexible, pero con límites establecidos que ellos lo saben muy bien, lo que pueden y no pueden hacer. Ellos pueden pedir permiso para ir al baño, pedir permiso para escuchar música, pedir permiso para comerse algo, pero pedir permiso: "¿Profe puedo comer?", "sí" yo les digo; "Claro que sí", "¿profe puedo ir a traer tal cosa", "si", "¿profe puedo ir al baño?", "sí", pero tienen un tiempo establecido para ir al baño. (TED2, 2016, p. 1)

Al respecto, los estudiantes colaboradores también se refieren a la autoridad flexible del docente en cuestiones académicas como la posibilidad de moldear las actividades pedagógicas de acuerdo a los gustos e intereses del estudiantado, así lo indica el siguiente estudiante:

Él siempre nos decía: "Escoger el tema que ustedes desean", nos dejaba a la libertad, él nunca nos decía: "Tienen que hacer una maqueta, o tienen que hacer algo", él nos dejaba la libertad de desarrollar el, proyecto o la actividad que uno [...] mientras se viera creativo. (TEE, 2016, p. 3)

Por otro lado, la dinámica áulica es también un reflejo de la disciplina flexible con la que trabaja el DSE: "Las clase con el profesor varían diariamente ya que en ocasiones pueden ser clases serias donde se enfoca en la materia y en otras situaciones son dinámicas y se vacila mucho" (TNE, 2016, p. 5). Además, el comportamiento y el uso del espacio denotan también la flexibilidad del DSE, en el subapartado "Construyendo jerarquías" se pudo constatar que la separación de espacios entre DSE y los estudiantes también marca una lógica de poder.

La flexibilidad del poder es localizable en las experiencias estudiantiles del DSE en dos figuras docentes, la primera de la secundaria -el docente Guadamuz- (TED1, 2016, pp. 11-12) y la segunda -quizá la más impactante- de la universidad, aunque es más perceptible esa autoridad flexible durante la etapa universitaria:

[Docente universitario:] Otro que también fue de Historia Universal, Carlitos, terminando con nosotros murió, de SIDA, y nos impactó tanto porque las clases de él era, si era civilizaciones antiguas él llevaba hasta, de todo, esculturas, mantas de lo que fuera, de la India, de esto, porque él viajaba mucho, y las exposiciones que nos lográbamos montar con él eran así de, como de película, nos permitía que nos vistiéramos, si era de faraón, o de Maya, o de emperadora Inca, pero las clases de él eran muy dinámicas, y nos traía mucho material y materia, y nos daba, y nos regalaba, nos decía: "No, no me lo paguen, yo se los regalo, tome le traigo estas filminas, tome le regalo esto" y las clases eran muy locas, con él, locas en el sentido que él era muy abierto a cualquier cosa, él decía: "No, hoy no vamos hacer tal cosa, vamos hacerlo en tal lado". (TED1, 2016, p. 30) 


\section{Afectividad-academicismo: equilibrio educativo}

Como último tipo de equilibrio del DSE se encuentra la forma genérica de concebir la educación, esta noción totalizadora se puede colegir del conjunto absoluto de datos que se obtuvieron en la investigación. El DSE evidencia poseer una concepción de la educación que va más allá de los simples o complejos actos de la aprehensión cognoscitiva; así para el DSE existe una carga emocional-afectiva-social-interaccional en toda la dinámica educativa. Por lo tanto, al solicitarle que caracterizara a docentes que marcaron su experiencial estudiantil se obtuvo un conjunto de calificativos que tienden a coincidir con los calificativos que el DSE espera ser recordado por sus estudiantes, véase el siguiente tabla:

TABLA 5

Calificativos docentes.

\begin{tabular}{|c|c|}
\hline $\begin{array}{l}\text { Calificativos con los que el DSE } \\
\text { recuerda a sus profesores idealizados }\end{array}$ & $\begin{array}{l}\text { Calificativos con los que el DSE desea } \\
\text { ser recordado }\end{array}$ \\
\hline Respeto & Apasionado por la docencia \\
\hline Presencia & Interesado en la actualización académica \\
\hline Autoridad & Accesible \\
\hline Inspiración & "Ogro feliz, ogro amable" \\
\hline Destreza académica y pedagógica & Simpático \\
\hline Creatividad & Respetuoso \\
\hline Dinamismo & Cariñoso \\
\hline Improvisación & Comprensivo \\
\hline Puntualidad & Enseñanza de valores \\
\hline Afectividad (saludar, vacilar) & Sabe lo que enseña \\
\hline Atención al estudiante & \\
\hline
\end{tabular}

Fuente:Elaboracion propia (TED1, 2016, pp. 29-31; TED1, 2016, pp. 14-15).

Como se puede observar en los listados anteriores, no existe un predominio academicista, sino más bien lo que se privilegia son los calificativos que refieren a la afectividad, a la emocionalidad, a la conciencia sobre el otro, son caracterizaciones socioafectivas, de interacción y de socialización. Asimismo, estas nociones sobre docentes y sobre sí mismo, reflejan del DSE su tendencia hacia una conceptualización educativa que conjuga la afectividad y el academicismo, comprendiendo así el fenómeno educativo más que como un acto técnico, como una práctica de socialización humana. Así lo señala el DSE:

Agradezco que ellos logren captar lo que yo quiero que entiendan de la vida, que no es materia, que hago yo con que me reciten [...], yo que hago con que me reciten eso de memoria si no me tienen respeto, no me tienen cariño, y yo parto mucho del cariño (TED2, 2016, p. 14).

\section{CONCLUSIONES}

Tan complejo es el ambiente áulico que las temporalidades presente y pasado confluyen en ese espacio, tanto las experiencias pasadas del docente como las del estudiantado están deambulando en ese "minúsculo" espacio; y en ciertos momentos los destellos del pasado de cada sujeto interactuante se asoman en las dinámicas áulicas. Lejos de pretender contener la última versión definitiva, el análisis expuesto hasta aquí se plantea como un punto de partida para múltiples formas interpretativas del actuar docente que intenten explicar un fenómeno tan complejo como la dinámica e interacciones áulicas, y ante todo, las diversas formas educativas del sentir, del hacer y del ser. 
De acuerdo con lo anterior, el análisis realizado deja una serie de puertas abiertas en torno a múltiples temáticas que se desprenden, quedan incompletas y dan paso a universos posibles de investigación. Cabe preguntarse en futuras investigaciones sobre temáticas como la influencia de las experiencias familiares del docente o la docente en la gestión de un clima de clase, así también interrogarse sobre las experiencias estudiantiles y familiares de los estudiantes que se puedan ver reflejadas en el comportamiento áulico; importante si se considera el aula un espacio en el cual confluyen el pasado y el presente de los actores interactuantes. Es indispensable orientar las investigaciones hacia estudios etnográficos que posibiliten conocer en el campo las dinámicas áulicas, los comportamientos, las interacciones, los gestos, la corporalidad así como los lenguajes, las frases y demás del quehacer cotidiano educativo.

Finalmente, cabe preguntarse de qué sirven las investigaciones que proponen metodologías educativas, planes didácticos, nuevos programas educativos sino se conoce cómo enfrentan la realidad educativa el conjunto de docentes y estudiantes, cómo se comunican, cómo interactúan, cómo sienten y se emocionan, y por lo tanto ¿cuáles serían las formas estratégicas para tornar significativos los conocimientos no desde el academicismo sino desde la emocionalidad?

\section{REFERENCIAS}

Alliaud, A. (1998). El maestro que aprende. Revista Ensayos y Experiencias, 4(23), 1-8. Recuperado el 18 de marzo del 2016 de https://ecaths1.s3.amazonaws.com/campodelapractica/1486857112.El\%20 maestro\%20que\%20aprende.docx

Alliaud, A. (2004). La experiencia escolar de maestros "inexpertos". Biografías, trayectorias y práctica profesional. Revista Iberoamericana de Educación, (34/3). Recuperado el 31 de marzo del 2016 de: http://rieoei.org/deloslectores/784Alliaud.PDF

Berreda, M. S. (2012). El docente como gestor del clima del aula. Factores a tener en cuenta (Trabajo Fin de Máster). Universidad de Cantabria, España. Recuperado el 09 de febrero del 2016 de: http://repositorio.unican.es/xmlui/bitstream/handle/10902/1627/Barreda\%20Gómez,\%20Mar\%C3\%Ada\%20 Soledad.pdf?sequence $=1$

Durkheim, É. (2002). Éducation et sociologie. (J-M. Tremblay, Ed.). Québec: Université du Québec. Recuperado el 27 de noviembre del 2015 de: http://www.uqac.uquebec.ca/zone30/Classiques_ des_sciences_sociales/index.html

Freud, S. (2009) 31 Conferencia. La descomposición de la personalidad psíquica. (O. Chávez, Ed.). Escuela Nacional de Artes Plásticas, UNAM. Recuperado el 18 de mayo del 2016 de: http://bibliopsi.org/docs/materias/obligatorias/CFG/adolescencia/grassi/Textos\%20puente/32a-Conferencia-Freud-Sigmund-Tamano-Carta.pdf

Go, N. (2009). Perspectives sur l'écoute en éducation. Le Journal de Chercheurs, 8. Recuperado el 18 de mayo del 2016 de: http://www.barbier-rd.nom.fr/n.go.perspectivessurlecoute.pdf

Hidalgo-Torres, A. J. (2016). Análisis de las experiencias estudiantiles vividas por el docente y su influencia en la gestión del clima socioafectivo de su clase en el presente. [Un estudio de caso con un docente de Estudios Sociales del Liceo de Cot, durante el segundo semestre del año 2016] (Tesis de Licenciatura). Universidad Estatal a Distancia, Costa Rica.

Jackson, P. W. (1996). La vida en las aulas. España: Ediciones Morata y Fundación Paideia.

Mejía, A. y Ávila, L. A. (2009). Relaciones sociales e interacción en el aula en secundaria. Revista Mexicana de Investigación Educativa, 14(41), 485-513. Recuperado el 09 de febrero del 2016 de: http:// www.repositoriodigital.ipn.mx/bitstream/handle/123456789/6572/Amalia_Arturo_Publicada. pdf? sequence $=1$ 
Núñez, J. P. (1998). Aprendizaje inconsciente. Condicionamiento a estímulos visuales subliminales (Tesis Doctoral). Universidad Pontifica Comillas Madrid, España. Recuperado el 17 de mayo del 2016 de: https://dialnet.unirioja.es/servlet/tesis?codigo $=392$

Ortega, R. (1990). El grupo aula como sistema de relaciones socioafectivas. Investigación en la escuela, (10), 51-60.

Pérez, O. (2012). Algunos porqués cognitivos del análisis semiótico: Una aproximación a las confluencias entre semiótica y psicología cognitiva. ZER, 17(33), 101-117. Recuperado el 17 de febrero del 2016 de: http://www.investigacionenlaescuela.es/articulos/10/R10_4.pdf

Reis, P., y Climent, N. (2012). Narrativas de profesores: reflexiones en torno al desarrollo personal y profesional. España: Universidad Internacional de Andalucía. Recuperado el 20 de enero del 2016 de: http://repositorio.ul.pt/bitstream/10451/9568/1/Narrativas\%20de\%20profesores.pdf

Román, D., Martínez, J., y Pérez, C. (1999). Interacción en el aula: de lo cognitivo a lo afectivo. Aula, (11), 205-216. Recuperado el 17 de febrero del 2016 de: http://revistas.usal.es/index.php/0214-3402/ article/view/3526/3548

Sarramona, J. (2008). Teoría de la educación. Barcelona, España: Editorial Ariel.

Torres, J. (1996). La práctica reflexiva y la comprensión de lo que acontece en las aulas. [Prólogo a la edición española]. En; P. W. Jackson, La vida en las aulas. España: Ediciones Morata y Fundación Paideia. 